\title{
Mechanical properties of hot curing acrylic resin after reinforced with different kinds of fibers
}

\author{
Zbigniew Raszewski", ", Danuta Nowakowska² \\ ${ }^{1}$ Zhermapol ${ }^{\circledR}$,Warsaw, Poland \\ ${ }^{2}$ Prosthetic Dentistry and Dental Materials Medical Academy in Wroclaw, Poland
}

Email address:

zbigniew.raszewski@zhermapol.pl(Z. Raszewski), danutanowakowska2@gmail.com(D. Nowakowska)

To cite this article:

Zbigniew Raszewski, Danuta Nowakowska. Mechanical Properties of Hot Curing Acrylic Resins after Reinforced with Different Kinds of Fibers. International Journal of Biomedical Materials Research. Vol. 1, No. 1, 2013, pp. 9-13. doi: 10.11648/j.ijbmr.20130101.12

\begin{abstract}
Background. Acrylic resins used in restorative dentistry are the most popular denture base material, because they have good optical properties and small solubility in body fluids. However their mechanical properties are limited and therefore acrylic resins require different methods of reinforcement one of which can be application of different kinds of fibers. Objectives. To investigate the effect of various fibers on the flexural properties of hot curing acrylic resins after it was broken and reconnected with cold curing material reinforced with polyethylene and glass fibers.Material and Methods. Villacryl H Plus hot curing material after curing was broken and reinforced with various unidirectional fibers to improve its resistance. The fibers' surface was pretreated with methyl methacrylate solution. Control specimens did not contain reinforced fiber. Flexural properties of reinforced acrylic resins (AFRAR) were determined in dry condition after 24 hours at $23^{\circ} \mathrm{C}$ and after 28 days water immersion at $37^{\circ} \mathrm{C}$. The test was performed by a three - point bending test using Instron type 4411 tensile testing machine.Results. Flexural resistance of fiber reinforced with acrylic resin (FRAR) increased after using fiber bundle in the sample. After 28 days of water immersion polyethylene fibers had better flexural properties compared to glass fibers. It could be connected with better polyethylene resistance in water conditions. Conclusions. Unidirectional polyethylene and glass fibers, are good application in restorative dentistry and the mechanical properties of hot curing acrylic resin increase after repairing process with cold curing resin.
\end{abstract}

Keywords: Polyethylene Fibers, Glass Fibers, Acrylic Resin, Mechanical Properties

\section{Introduction}

Dental prostheses are on second place in different appliances that are most frequently used by elderly population, just after glasses. It is connected with the number of elderly people (60 and more years old) increasing within the population. Today dental prostheses are predominantly made of methyl methacrylate polymer which has proven to be the most reliable denture base material with biocompatibility, easy handling process, good resistance to food and organic fluid, and natural appearance. This kind of process was introduced almost 70 years ago, and it is still very popular because operate with gypsum form which can be filled with acrylic dough is easy to operate with[1,2].

Despite many advantages, poly(methyl methacrylate) has very poor mechanical resistance (flexural strength, impact resistance). In some clinical cases denture are breaking down very easily and it is necessary to repair them with cold curing polymers. This repair deteriorates in strength over a short period of time and so reduces the clinical performance of the prosthesis. This kinds of polymer are different in there chemical and physical properties in comparison with the hot curing.

In the literature there is a lot of articles about repairing processes with cold curing acrylic resins. All the results show that performance of a new bond between cold curing resins and hot curing resins is weaker in flexural resistance than original hot curing materials. Off course this depends on the curing cycle (temperature, pressure, geometric factors), but the bond nevertheless has between $46-67 \%$ of strength compared with the intact specimens[3, 4, 5].

There are some alternatives to improve mechanical properties of acrylic resins, one of them are different kind of fibers: glass, aramid, polyethylene, carbon[1-10].

Today the most acceptable fibers for dental polymer reinforcements are glass fibers, because of their good aesthetics and good bonding with polymers via silane 
coupling agents. Also, they can easily be adapted to the desired shape and length which is then suitable for incorporation into denture base of polymer material[1,2,7,10-12]. The second possibility are the polyethylene fibers with surface modified by cold plasma. This kind of process with very high temperature can also change the surface of polyethylene[2, 5, 7]. After such process this kind of material is ready for wetting and bonding with acrylic resins. Moreover, results of scientists who made investigations with fibers, indicate improvement of acrylic resins[1-12].

In scientific literature (Pub Med) it is possible to find an article about acrylic resins that after breaking was repaired with cold curing resin strengthened by incorporation of polyethylene fibers. This paper described the clinical situation without mechanical tests[13].

\subsection{Aim of the Study}

The main goal of this study was the assessment of flexural strength of dental hot curing base polymers, reinforced after breaking with polyethylene, and silane pre-impregnated glass fibers.

\section{Materials and Methods}

\subsection{Materials}

Test specimens were made of hot curing resins (Villacryl H Plus Zhermapol) in two phases:

- Liquid, 5\% ethylene glycol dimethacrylate (EGDMA) and 95\% methyl methacrylate (MMA) stabilized with $50 \mathrm{ppm}$ hydrochinone (MEHQ)

- Powder, contains poly(methyl methacrylate) polymer, main particles granulation $60 \mu \mathrm{m}$, with $0.3 \%$ of benzoyl peroxide (BPO).

- $\quad$ For the repairing process of hot curing resins cold curing resins were used, (Villacryl S, Zhermapol) and contained:

- Liquid, 5\% ethylene glycol dimethacrylate (EGDMA) and 95\% methyl methacrylate (MMA), $0.5 \%$ N,N, dimethyl-p-toulidine, stabilized with 50 ppm hydrochinone (HQ).

- Powder containing poly(methyl methacrylate) polymer with citrate plasticizes, main particles granulation $40 \mu \mathrm{m}$, with $0.5 \%$ of benzoyl peroxide (BPO).

Unidirectional monofilament polyethylene fibers Construct (Kerr) modified with cold plasma, and glass fibers (Atkin \& Pearce) were used for acrylic resin reinforced after breaking.

Glass fibers were washed in hot water and silanisated with $\gamma$-metacryloxypropyl-trimethoxysilane (Sigma-Aldrich Co., St. Louis, MO, USA). The fibers' mechanical and physical properties according to the manufacturers were: 18 $\mu \mathrm{m}$ diameter, bundles $2 \mathrm{~mm}$ bright, and $0.2 \mathrm{~mm}$ tick.

\subsection{Preparation of the Specimens for Study of Mechanical Properties}

\subsubsection{Preparation of Hot curing Samples}

Tests specimens with dimensions $3.3 \pm 0.1,10.0 \pm 0.1$ and $65.0 \pm 0.1 \mathrm{~mm}$ were prepared in stainless steel molds[14]. In separate glass container $15 \mathrm{~g}$ of Villacryl H Plus (hot curing AR) was mixed with $6 \mathrm{~g}$ methacrylic monomer using electronic balance. After 15 minutes each mold was filled with the acrylic dough. The forms with acrylic resins were covered on both sides with two metal slabs, and put in to the press (Zhermack). Pressing process took 10 minutes, and after that time molds were screwed in to the metal frame and put in to the hot water $\left(60^{\circ} \mathrm{C}\right)$. Polymerization process was made according to manufacture instruction (30 minutes $60-100^{\circ} \mathrm{C}, 30$ minutes in boiling water). After slowly cooling, at room temperature frame was opened and acrylic specimens were taken off. For the experiments 96 plates of resin were prepared. Each specimen was broken down in the middle of his length with the joint ends rounded off as this type of joint preparation has been shown to provide the strongest repair. For each repair specimen, an index was made by making an open-ended stone mold that allowed the repair ends to be moved providing a $2 \mathrm{~mm}$ gap between them. The gap was necessary for the cold curing resin[15].

At the end of the samples' surface a rectangular gap was cut with metal bur and micromotore (Zhermack) (Fig.1).

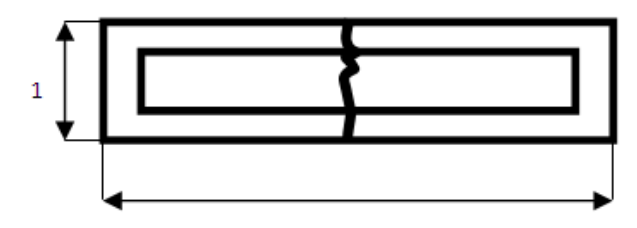

65

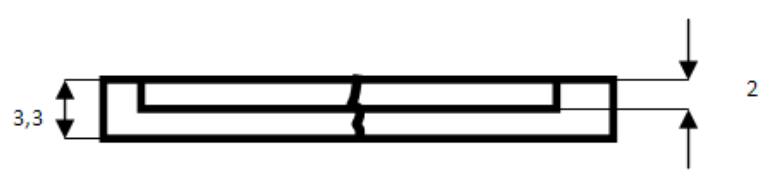

Figure 1. Rectangular hole inside acrylic specimen for fiber placement. Dimension in $\mathrm{mm}$

\subsubsection{Preparation of Glass Fibers}

The $\quad 0.5 \% \quad \gamma$-metacryloxypropyl-trimethoxysilane solution was prepared with mixing $0.5 \mathrm{~g}$ silane, $99.5 \mathrm{~g}$ of isopropanol and $0.5 \mathrm{~g}$ of acetic acid. One meter of glass fibers was put into such solution, and mixture was stirred for 3 hours in $23^{\circ} \mathrm{C}$. After that the fibers were washed with distilled water to removed access of silane and dried in oven in $60^{\circ} \mathrm{C}$ for 12 hours. Storage in elevated temperature was necessary for finishing silanization process.

\subsubsection{Preparation Samples with Fibers}

All samples prepared according point 1.2.1 were divided into 8 groups, each of them containing 12 samples:

A. Hot curing resins Villacryl $\mathrm{H}$ were glued with cold curing resins Villacryl S after breaking 
B. A group where polyethylene fiber ( $5 \mathrm{~mm}$ long) was placed inside the hole and soaked with monomer.

C. A group containing samples of polyethylene fibers with construct composite resins. Polyethylene fibers were covered by resins and polymerized with halogen lamp Cromalux for 20 seconds in order for the curing process to take place. After that they were positioned inside an acrylic plate. This acted as a wetting agent for the other resin.

D. Group with Construct fibers soaked with Villacryl ULS. This is a material on the basis of MMA and urethane acrylate and is similar to a lacquer for wetting glass fibers. After immersion in lacquer all fibers were light cured using a halogen lamp. Curing fibers were put inside acrylic samples.

E. Silanized glass fibers (SGF) wetted with methacrylic monomer from Villacryl S.

F. SGF covered by Construct resins and cured for 20 second with halogen lamp.

G. Glass fibers with silane on the surface soaked with Villacryl ULS and cured in light for 20 seconds.

Holes in all the samples with fibers inside them were filled with cold curing resins Villacryl S. After 5 minutes when resins was in the soft rubber stage, samples were immersed in water $45^{\circ} \mathrm{C}, 2.5$ bar for 15 minutes. After curing was complete the samples were removed from their molds and grounded with grinding paper P1200 (15.3 $\mu \mathrm{m}$, silicon carbide paper Norton Vulcan, Saint Gobain, Kolo, Poland).

For each groups (from A to G) 12 samples were prepared and divided into two groups. A half of the samples (6 samples) in each group were stored in a water-bath at $37 \pm 1^{\circ} \mathrm{C}$ for 28 days, and the other half was kept at air $23^{\circ} \mathrm{C} \pm 1^{\circ} \mathrm{C}$ and humidity $50 \%$ for 24 hours.

\subsection{Flexural Properties of Methacrylic Polymer Reinforced with Different Kind of Fibers}

Flexural properties of dry and wet specimens were determined using a three - point bending test with Instron 4411 testing machine H 2097 (Instron Corp., Anglia)) and Series IX Automated Materials Testing System Version 5.34.00 (a computer program). The three- point bending test was carried out by water immersion in temperature of $37 \pm 1^{\circ} \mathrm{C}$. The specimens were bent in a three - point transverse testing rig with $50 \mathrm{~mm}$ between the two supports and with a constant cross head speed of $5.0 \mathrm{~mm} / \mathrm{min}[14]$. The ultimate transverse strength $(\mathrm{S})$ was calculated from (1):

$$
\mathrm{S}=(3 \mathrm{FL}) / 2 \mathrm{bh}^{2}
$$

where ' $\mathrm{F}$ ' is the applied load (N) at the highest point of the load - deflection curve, ' $\mathrm{L}$ ' is the span length $(50.0 \mathrm{~mm})$, ' $\mathrm{b}$ ' is the measured width of the test specimen, and ' $h$ ' is the measured thickness of the test specimen. The dimensional measurements were made with digital micrometer Links (Japan), (standard measurement uncertainly $0.01 \mathrm{~mm}$ ).
The flexural modulus (E) was calculated from (2):

$$
\mathrm{E}=(13 \mathrm{~F}) / 4 \mathrm{bh} 3 \mathrm{~d}
$$

where ' $d$ ' is the deflection corresponding to load ' $F$ ' at the point in the straight line portion of the trace.

\section{Statistical Analysis}

The results of the measurements of ten different groups were investigated by independent sample test $\mathrm{T}$ at $95 \%$ significance level using a statistical software package (SPSS, Statistical Package for the Social Sciences for Windows, 15.0.1, Chicago, IL USA).

Table 1. Flexural strength of hot curing resins repaired with polyethylene fibers

\begin{tabular}{lc}
\hline \multicolumn{1}{c}{ Material } & Flexural strength \\
\hline Polyethylene fibers wet with MMA 24 h & $110.4 \pm 4.5 \mathrm{MPa}$ \\
Polyethylene fibers wet with MMA 28 days & $108.2 \pm 3.7 \mathrm{MPa}$ \\
Polyethylene fibers wet with Construct resin 24 h & $129.2 \pm 3.1 \mathrm{MPa}$ \\
$\begin{array}{l}\text { Polyethylene fibers wet with Construct resin } 28 \\
\text { days }\end{array}$ & $124.5 \pm 4.1 \mathrm{MPa}$ \\
Polyethylene fibers wet with Villacryl ULS 24 h & $113.5 \pm 2.9 \mathrm{MPa}$ \\
Polyethylene fibers with Villacryl ULS 28 days & $115.6 \pm 3.8 \mathrm{MPa}$ \\
Villacryl H 24 h & $68.3 \pm 4.2 \mathrm{MPa}$ \\
Villacryl H 28 days & $63.2 \pm 3.9 \mathrm{MPa}$ \\
\hline
\end{tabular}

Table 2. Flexural strength of hot curing resins repaired with glass fibers

\begin{tabular}{lc}
\hline \multicolumn{1}{c}{ Material } & Flexural strength \\
\hline Glass fibers wet with MMA 24 h & $112.4 \pm 4.3 \mathrm{MPa}$ \\
Glass fibers wet with MMA 28 days & $105.2 \pm 4.4 \mathrm{MPa}$ \\
Glass fibers wet with Construct resin 24 h & $135.3 \pm 5.1 \mathrm{MPa}$ \\
Glass fibers wet with Construct resin 28 days & $123.1 \pm 4.1 \mathrm{MPa}$ \\
Glass fibers wet with Villacryl ULS 24 h & $136.9 \pm 3.7 \mathrm{MPa}$ \\
Glass fibers wet with Villacryl ULS 28 days & $121.6 \pm 3.5 \mathrm{MPa}$ \\
Villacryl H 24 h & $68.3 \pm 4.2 \mathrm{MPa}$ \\
Villacryl H 28 days & $63.2 \pm 3.9 \mathrm{MPa}$ \\
\hline
\end{tabular}

\section{Results}

Ultimate flexural strengths (S) and elastic module (E) of polyethylene fibers inside polymers before and after water immersion are presented in Tables 1 and 3. The same values for modification of the samples with glass fibers are presented in Tables 2 and 4. The flexural properties of acrylic resins after breaking were generally improved when fibers were added but their strength was dependent on the position of the fiber inside the sample. An increase in the flexural strength is possible if the fibers are placed in opposite direction to the breaking force[16]. 
The best results were obtained with glass fibers wetted with methyl methacrylate. However immersion in water for 28 days slightly decreased the mechanical properties of acrylic resins filled with glass fibers compared to the specimens with polyethylene fibers[17].

Table 3. Elastic module of hot curing resins repaired with polyethylene fibers

\begin{tabular}{lc}
\hline \multicolumn{1}{c}{ Material } & Flexural strength \\
\hline Polyethylene fibers wet with MMA 24 h & $3192 \pm 38 \mathrm{MPa}$ \\
Polyethylene fibers wet with MMA 28 days & $3054 \pm 41 \mathrm{MPa}$ \\
Polyethylene fibers wet with Construct resin 24 h & $4256 \pm 39 \mathrm{MPa}$ \\
$\begin{array}{l}\text { Polyethylene fibers wet with Construct resin 28 } \\
\text { days }\end{array}$ & $4198 \pm 42 \mathrm{MPa}$ \\
Polyethylene fibers wet with Villacryl ULS 24 h & $3789 \pm 36 \mathrm{MPa}$ \\
$\begin{array}{l}\text { Polyethylene fibers with Villacryl ULS 28 days } \\
\text { Villacryl H 24 h }\end{array}$ & $3652 \pm 38 \mathrm{MPa}$ \\
Villacryl H 28 days & $1860 \pm 44 \mathrm{MPa}$ \\
\end{tabular}

Table 4. Elastic module of hot curing resins repaired with glass fibers

\begin{tabular}{lc}
\hline \multicolumn{1}{c}{ Material } & Elastic module \\
\hline Glass fibers wet with MMA 24 h & $3245 \pm 33 \mathrm{MPa}$ \\
Glass fibers wet with MMA 28 days & $3124 \pm 29 \mathrm{MPa}$ \\
Glass fibers wet with Construct resin 24 h & $4532 \pm 45 \mathrm{MPa}$ \\
Glass fibers wet with Construct resin 28 days & $4351 \pm 48 \mathrm{MPa}$ \\
Glass fibers wet with Villacryl ULS 24 h & $3376 \pm 32 \mathrm{MPa}$ \\
Glass fibers wet with Villacryl ULS 28 days & $3124 \pm 36 \mathrm{MPa}$ \\
Villacryl H 24 h & $1860 \pm 44 \mathrm{MPa}$ \\
Villacryl H 28 days & $1654 \pm 47 \mathrm{MPa}$ \\
\hline
\end{tabular}

\section{Discussion}

Denture fractures are common in daily practice, causing inconvenience to a patient and dentists. This means that denture repairs should have adequate strength, dimensional stability and color match, and should be easily and quickly performed as well as being relatively inexpensive[18].The aim of this study was to evaluate the effect of different kinds fiber used for repair hot curing resins after breaking. A clinical study has shown that a glass fiber reinforced repaired denture and did not allow re-fracture in the same place as the previous repair[2, 19, 20].

The results of many investigations indicate that the fibers' position inside the sample is very important. If glass fibers bands are cut into short segments they do not have a big effect on improving the mechanical properties. Their flexural resistance however depends on the environmental conditions. Furthermore, increasing the flexural strength is possible if the fibers are in opposite direction to the breaking force.

All the specimens exhibited lower transverse strength with an increase water immersion time, because of plasticizer effect due to uptake of water. Additionally glass fibers have shown a reduction in ultimate flexural strength after long water absorption[2, 11, 18] and approximately a half of the initial value for glass fibers sized with cross linked PMMA and composite materials.

On the other hand glass fiber containing $\mathrm{OH}$ groups are covered by silane, which can make them more susceptible to water (silane hydrolization process in water). The poor impregnation of fibers with composite can increase water absorption[20].

Another way in which resin can be reinforced after breaking are metal wires strengtheners. Kostoulas I. E. suggests that metal wire or glass fiber which is used for reinforcement can restore only the original fracture force at full or half of a length; deflection and toughness remaining significantly lower. Based on this study, it appears that the group reinforced with full lengths of metal wire offered the best potential for reinforcement $[21,22]$. The same scientists (I.E Kostoulas, T. Kavoura, M.J. Frangou, G.L. Polyzois) have made another investigation of breaking hot curing resins with glass fibers wetted with MMA during 180 second, or without such process. Their results suggest that wetting process is very important for good adhesion between fibers and resin. Flexural strength without methyl methacrylate soaking was $75.8 \pm 9.2 \mathrm{MPa}$ and after such procedure was $124.4 \pm 12.5 \mathrm{MPa}[23]$. This result is similar to the one achieved by us since when glass fiber were wetted with MMA flexural strength was $112,4 \pm 4.3 \mathrm{MPa}$. Wetting with MMA could be insufficient if the sample are stored in an open air for too long. Some of methyl methacrylate can evaporate making the surface of resin too dry. In our study when methyl methacrylate was used with urethane acrylate (Villacryl ULS) results improved $(136.9 \pm 3.7 \mathrm{MPa})$.

K. K. Narva and P. K. Vallittu made clinical trials of denture reinforced with glass fibers. During the period of 4 months, $88 \%$ of denture was in no need for adjustment at the region of partial fiber reinforcement and the clinical condition of the dentures was good. Glass fibers did not irritate the oral mucosa. In case of re-fracture or hairline fracture if positioning of the partial fiber reinforcement was incorrect or the reinforcement had been used incorrectly wetting of the reinforcement with denture base resin proved inadequate[24].

Standard deviation in flexural properties within groups may partly be attributed to specimen variation. Even if the same laboratory process was followed in preparation of specimens there are several undesirable factors causing specimen variations during preparation such as wetting fiber surface by the polymer and monomers, PMMA penetration between the fibers, micro porosity on the border of fiber and polymer or sizing process. However, differences between specimens can best be explained by placement of fibers.

\section{Conclusions}

Unidirectional polyethylene and glass fibers after surface 
pretreated with methacrylic polyfunctional monomers may find application in restorative dentistry since mechanical properties of acrylic resins increase when used as a denture base material.

\section{References}

[1] J.J. Gangadhar, I. Shah "Flexural strength of heatpolymerized polymethyl methacrylate denture resin reinforced with glass, aramid, or nylon fibers" J. Prosthet. Dent., vol. 86(4), pp 424-7, 2001, Oct.

[2] P.K. Vallittu "A review of fiber-reinforced denture base resins" J. Prosthodont., vol. 5(4), pp 270-6, 1996 Dec.

[3] A. Leong, A. A. Grant, "The transverse strength of repairs in polymethyl methacrylate", Aus. Dent. J., vol.16(4), pp 232-4, 1971.

[4] M. Berge, "Bonding strength of intact and repaired denture base resins", Acta Odontol. Scand., vol. 41(3), pp 187-91, 1983.

[5] D.L. Guteridge," The effect of including ultra -high modulus polyethylene fiber on the impact strength of acrylic resins", Br. Dent. J., vol.164, pp 177-80, 1988.

[6] C.C van Heumen, C.M. Kreulen, E.M. Bronkhorst , E. Lesaffre, N.H. Creugers, "Fiber-reinforced dental composites in beam testing", Dent. Mater., vol. 24(11): pp 1435-43, 2008 Nov.

[7] K.K Narva, L.V. Lassila, P.K. Vallittu, "The static strength and modulus of fiber reinforced denture base polymer". Dent. Mater., vol. 21(5): pp 421-8, 2005 May.

[8] P. Gajdus, W. Hędzelek, S. Joniak,” Próby wykorzystania włókien aramidowych Kevlar w zbrojeniu polimerów akrylowych - część I. Badania mechaniczne siły połączenia akrylowych kształtek z tkaniną Kevlar". Prot. Stom., vol. 53(4), pp 235-241, 2003.

[9] P. Gajdus, W. Hędzelek, S. Joniak,” Próby wykorzystania włókien aramidowych Kevlar w zbrojeniu polimerów akrylowych - część II. Badanie wytrzymałości akrylowych płyt podniebiennych zbrojonych tkaniną Kevlar", Prot. Stom., vol. 53(5), pp 302-306, 2003.

[10] A. Rahamneh, A. Abdellateef, T. Mineizel, "Transverse strength of acrylic resins denture base material after the addition of different fibers", Pakist. Oral. and Healf. J., vol. 27(1), pp 116-118, 1999.

[11] G. Uzun, F. Keyf, "The effect of fiber reinforcement type and water storage on strength properties of a provisional fixed partial denture resin". J. Biomater. Appl., 2003, vol. 17(4), pp 277- 286.
[12] I.E. Kostoulas, V.T. Kavoura, M.J. Frangou, G.L. Polyzois, "The effect of length parameter on the repair strength of acrylic resin using fibers or metal wires", Gen Dent., vol. 56 (1), pp 51-5, 2008, Jan-Feb.

[13] O. Karacaer, O.M. Dogan, T. Tinçer , A. Dogan, "Reinforcement of maxillary dentures with silane-treated ultra high modulus polyethylene fibers", J. Oral. Sci., vol. 43(2), pp103-7, 2001 Jun.

[14] ISO 1567, Dentistry - denture base polymer, Geneva: International Organization for Standardization. 1999, pp $1-27$.

[15] D. Vojvodić, D. Komar, Z. Schauperll, A. Čelebić, K. Mehulić, D. Žabarović, "Influence of different glass fiber reinforcements on denture base polymer strength (Fiber reinforcements of dental polymer)", Med. Glas., vol. 6 (2), pp 227-234, 2009.

[16] L.V. Lassila, P.K. Vallittu, "The effect of fiber position and polymerization condition on the flexural properties of fiber reinforced composite", J. Contemp. Dent. Pract., vol. 54, pp, 14-26, 2004 May.

[17] V.M. Miettinen, P.K. Vallittu, D.T. Docent, "Water sorption and resin", J. Prosthet. Dent., vol. 77(5), pp 531-4, 1997.

[18] V. Ramos, D.A. Runyan, L.C. Christensen," The effect of plasma-treated polyethylene fiber on the fracture strength of polymethyl methacrylate", J. Prosthet. Dent., vol.76 pp 94-6, 1996.

[19] N.H. Ledizesky, C.F. Ho, T.W. Chow," Reinforcement of complete denture bases with continuous high performance polyethylene fibres", J. Prosthet. Dent., vol. 68, pp 934-9, 1992.

[20] K. L. Mitkal, "Silanes and Other Coupling Agents,", Brilll, Nederland, 2009, pp 46-59.

[21] I.E. Kostoulas, V.T. Kavoura, M.J Frangou, G.L. Polyzois, "The effect of length parameter on the repair strength of acrylic resin using fibers or metal wires", Gen. Dent., vol. 56(1), pp 51-5, 2008 Jan-Feb.

[22] H. Minami, S. Suzuki, H. Kurashige, Y. Minesaki, T. Tanaka," Flexural strengths of denture base resin repaired with autopolymerizing resin and reinforcements after thermocycle stressing", J Prosthodont., vol. 14(1), pp 12-8, 2005 Mar.

[23] I. Kostoulas, V.T. Kavoura, M.J. Frangou, G.L. Polyzois, Fracture force, deflection, and toughness of acrylic denture repairs involving glass fiber reinforcement J. Prosthodont., vol.17(4), pp 257-61, 2008 Jun.

[24] K.K. Narva, P.K. Vallittu, H. Helenius, A. Yli-Urpo, "Clinical survey of acrylic resin removable denture repairs with glass-fiber reinforcement", Int. J. Prosthodont., vol. 14(3), pp 219-24, 2001 May-Jun. 